\title{
Analysis of the Impact of Industrial Pollution Control Investment on Industrial Growth- Taking Shandong Province as an Example
}

\author{
Ren Shijia, Yin Xiuqing, Hu Zibo
}

\author{
Business School, Shandong University of Technology, Zibo 255000, China
}

\begin{abstract}
The historical data of industrial value added and industrial pollution control investment in sample area of Shandong Province from 2005 to 2018 were selected as the measurement samples, and the long-term investment in industrial added value and industrial pollution control was tested by co-integration test, error correction model and Granger causality test. Equilibrium relationships and short-term dynamic effects are studied. The results show that the investment amount of industrial pollution control investment for treating wastewater and waste gas has a long-term equilibrium relationship with industrial added value; for every $1 \%$ increase of industrial pollution wastewater treatment investment, industrial added value increases by 0.09\%; industrial pollution waste gas treatment investment For every $1 \%$ increase in the amount, the industrial added value will decrease by $0.03 \%$.Granger test results show that industrial added value and industrial wastewater treatment investment, industrial waste gas treatment investment are independent of each other, there is no Granger causal relationship.
\end{abstract}

Keywords - industrial development; industrial pollution; co-integration test; Granger causality.

\section{PREFACE}

With the rapid development of the industrial economy, the problem of environmental pollution has become more and more serious. About $75 \%$ of the pollutants in nature are produced by industrial enterprises ${ }^{[1]}$, the issue of environmental pollution control has received increasing attention. Shandong Province is China's economic province. In the past two decades, the total amount of GDP in Shandong Province has been at the forefront of the country. However, due to the large number of industrial enterprises in the province, the total industrial output value of Shandong Province has accounted for $40 \%-50 \%$ of the total GDP every year for the past ten years. Between 2005 and 2008, the proportion of Shandong's industrial economy exceeded $50 \%$, and in 2006 it reached the highest level of 52\%.In 2007, Shandong's industrial added value reached 134.127 billion yuan, and the total industrial output value exceeded that of industrial developed areas such as Jiangsu and Guangdong, ranking first in the country. The proportion of industry is so large, and the problem of industrial pollution in Shandong Province is also becoming increasingly prominent. Taking industrial wastewater discharge as an example, the data of wastewater discharge between 2000 to 2018 are analy zed. The results show that, except for individual years, the discharge of wastewater has decreased, such as: from 2001 to 2002 , it decreased from 235.271 million tons to 230.709 million tons. The discharge of wastewater in other years has increased year by year. The development of circular economy is the goal of our long-term development. In order to ensure that industrial economic development does not come at the expense of environmental pollution, investment in industrial pollution control in Shandong Province is also increasing

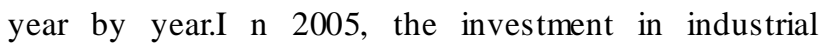
pollution control in Shandong Province was 402.53 million yuan, reaching 1465.64 million yuan in 2014, and by 2015 , the investment fell back to $1,264.63$ million yuan. Although the investment in industrial pollution control has declined in some years, overall, the investment in industrial pollution control in Shandong Province has been increasing with the increase of pollutant emissions.

Domestic scholars' research on industrial pollution is currently focused on the relationship between economic growth and pollution emis sions. Zhu Jianhua ${ }^{[2]}$ and others have studied the relationship between environmental protection investment and economic growth by establishing an error correction model, and concluded that environmental protection investment has a significant pulling effect on GDP. Environmental investment is the reason for GDP growth in the long run.Wu Yongchao, Xie Zhengjuan $^{[3]}$ Based on the state space model, using the industrial pollution control investment data from 2000 to 2014, it is estimated that the fluctuation coefficient of the elasticity coefficient of investment output of domestic 
industrial enterprises is 0.099 , which is mainly positive effect on economic growth.Fully fortunate ${ }^{[4]}$ Analyze China's industrial pollution control investment based on the experience of industrial pollution control in Japan that year, and clarify the necessity of industrial pollution control investment for the development of industrial enterprises.Lan Minghui [ 5 ] et al. By studying the relationship between industrial pollutant emissions and governance investment data and industrial output value, it is concluded that industrial economic development has higher requirements for industrial pollution control, and investment in industrial pollution control based on end-of-pipe investment is improved. Structure is the top priority of the business.Liu $\mathrm{Tao}^{[6]}$ evaluated the investment efficiency of industrial pollution control in Fujian Province, pointing out that the overall investment redundancy rate of industrial pollution control investment in Fujian Province in 2011 was $8.81 \%$.Nie Hualin and Chen Shaoqi ${ }^{[7]}$ The investment efficiency of industrial pollution control in the western region was evaluated. The results showed that the investment waste rate of industrial pollution control investment in the western region was $32.6 \%$.According to panel data of 10 provinces and cities, Chen Shihong ${ }^{[8]}$ et al. studied the relationship between China's industrial pollution control investment and economic growth, and concluded that when the investment growth of industrial pollution control is less than doubled and more than doubled, the pulling effect on economic growth is completely different.

The current research mainly regards the total investment in industrial pollution control as an indicator of the impact of research problems, and lacks a comprehensive consideration of the ratio between the various parts of the total investment and the contribution to the research questions.As a result, the conclusions obtained cannot fully reflect the real situation of the research problem, and have certain limitations.Based on the above considerations, this paper uses co-integration theory to analyze the industrial value added and industrial pollution control investment data of sample area in Shandong Province from 2005 to 2018, and study the industrial added value sequence of Shandong Province with industrial wastewater, waste gas, waste solidification, noise and other industrial pollution. The co-integration relationship between governance investment sequences reveals the interrelationship between industrial development and industrial pollution control investment.

\section{VARIABLE SELECTION AND MODEL INTRODUCTION}

\subsection{Cointegration analysis and error correction model}

Most scholars used regression analysis to study the relationship between two variables or multiple variables in the previous research on the relationship between industrial pollution control investment and economic growth. Since the sequence of economic variables in real life is mostly non-stationary, if you directly perform regression analysis, it is highly probable that "pseudo-regression" phenomenon ${ }^{9]}$, thus getting the wrong conclusion. In order to satisfactorily solve this problem, RFEngle and CWJGranger formally proposed co integration theory in 1987.Co-integration refers to the linear combination of two or more non-stationary time series variables, forming a stable time series.At this time, these non-stationary time series variables are said to have a co integration relationship or a long-term equilibrium relationship. The purpose of the co-integration test is to test whether there is such a long-term relationship between two or more variables, thereby preventing pseudo-regression. The economic significance is that although different variables have their own long-term fluctuation laws, if there is a co integration relationship between them, there must be a long-term stable relationship between them. On the contrary, if the long-term fluctuation laws between different variables are different and there is no co-integration relationship, then there is no such long-term stable relationship between them.

In reality, most of the variables that have a co integration relationship will evolve from an equilibrium state to a short-term equilibrium state in many cases. When we want to return it to the equilibrium state from the short-term deviation from equilibrium, we need to use error correction. model.

\subsection{Variable selection and data source}

This paper selects the industrial added value as a variable to measure the level of industrial development. Industrial added value is a new added value in the process of industrial enterprises' production activities, which can more accurately reflect the relationship between industrial enterprise development and industrial pollution control investment.Since industrial pollution is mainly composed of waste water, waste gas, waste residue and various noises generated during the production process, the industrial pollution control investment studied in this paper is divided into investment in wastewater treat ment, waste gas, waste solidification, noise and other pollution control.The investment data of Shandong Province Statistical Yearbook and the National Statistics Bureau of China in the period of 2005-2018 and the industrial pollution of different types of industrial pollution in Shandong Province were selected as the research basis.The industrial added value is in units of 100 million yuan, and the industrial pollution control investment is in 
units of 10,000 yuan.

Since the original data is logarithm, it does not change their orig inal co-integration relationship ${ }^{[10]}$, and can effectively eliminate the heteroscedasticity in the time series and the case where the order of magnitude of the independent variables is very different, so the industrial added value (iav), industrial wastewater treatment investment (iwt), industrial waste gas treatment Investment (iwg), industrial solid waste management investment (iws), industrial noise control investment (inc) and other industrial pollution investment (opi) logarith m, ie lniav, lniwt, lniwg, lniws, lninc and lnopi.

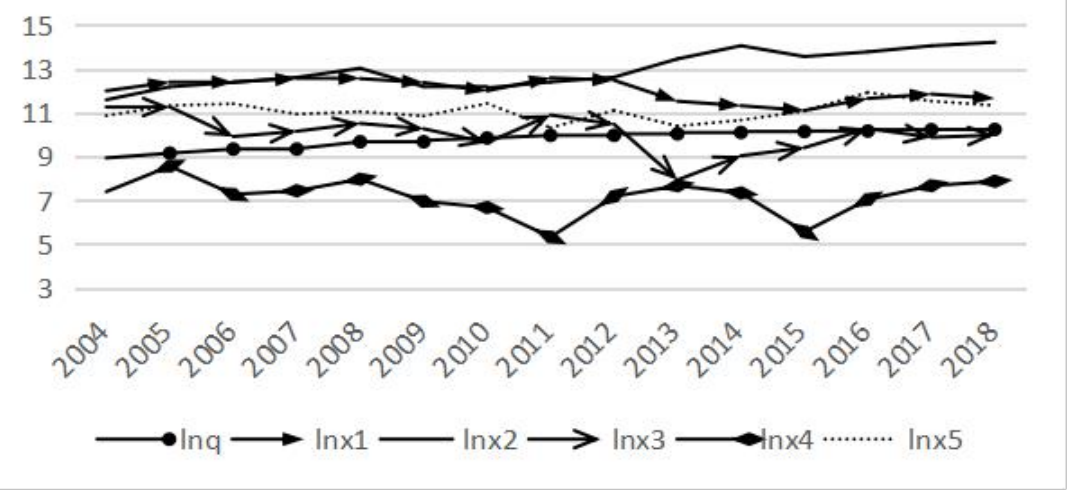

Fig.1: Timing diagram

It can be seen from the trend of the fold line in the time series diagram (Fig.1) that some variables are relatively stable, while some are obviously non-stationary, and the non-stationary variables have very similar periods of change, which is a typical feature of long-term equilibrium relations. Co-integration analysis can be performed on it.

\section{3 variable unit root test}

Unit root test for each time series variable before co-integration test of industrial added value and industrial pollution control investment sequence ${ }^{[\mathrm{xi}]}$ 。The common methods of unit root test are DF test, ADF test, etc., but because the DF test can not guarantee that the residual term in the test equation is white noise, Dickey and Fulle $r$ expand the DF unit root test method to generalize it to more general. The situation is the ADF (Augented Dickey-Fuller Test) test.The ADF (Augented Dickey-Fuller Test) test is the most commonly used test method in the current stationarity test.

The adf unit root test consists of the following three scenarios:

Case 1: A situation without an intercept term:

$\Delta x_{t}=(\rho-1) x_{t}-1+\sum_{i=1}^{k} \theta_{i} \Delta x_{i}-1+\varepsilon t$.

Case 2: A situation with only intercept items:

$$
\Delta x_{t}=\alpha+(\rho-1) x_{t}-1+\sum_{i=1}^{k} \theta_{i} \Delta x_{i}-1+\varepsilon t
$$

Case 3: A situation with both an intercept and a time trend term:

$$
\Delta x_{t}=\alpha+\beta t+(\rho-1) x_{t}-1+\sum_{i=1}^{k} \theta_{i} \Delta x_{i}-1+\varepsilon t .
$$

Using the ADF unit root test, the $t$ statistic is constructed first, and the value of the $t$ statistic is calculated. Then find the critical value at a given level of significance from the ADF threshold table and make a hypothesis test: $\boldsymbol{H}_{0}: \rho=1 ; H_{1}: \rho<\mathbf{1}$ The test begins with the third case, then with the second case, and finally with the first case.If the value of the test result $t$ statistic is greater than the critical value at a given significance level, accept the null hypothesis $H_{0}$, rejecting alternative hypotheses $H_{1}$ That is, there is a unit root in this sequence, which is a non-stationary sequence. Conversely, if the value of the $t$ statistic is less than the critical value at a given significance level, the null hypothesis with the unit root is rejected, and at this time, there is no unit root of the sequence, which is a stationary sequence. In order to make the residual term white noise, $\mathrm{k}$ lag variables are added to the model. When the time series is non-stationary, the stationarity of the first-order difference or the second-order difference is checked.If the first-order difference is a stationary sequence, then this variable asks for a first-order single-order sequence, denoted as I(1), and so on.When using EG co-integration test, we must first test the stability and unity of the variable. If both variables are non-stationary variables and the single order is the same, then the co-integration relationship may exist, but it is stable for itself. Sequences and sequences with different single orders cannot be co-integrated. The results of ADF test for each variable using Eviews software are shown in Table 1: 
Table.1: Variable sequence unit root test results (ADF test)

\begin{tabular}{cccccc}
\hline variable & Adf value & $\begin{array}{c}\text { Threshold } \\
(1 \%)\end{array}$ & $\begin{array}{c}\text { Threshold } \\
\text { value }(5 \%)\end{array}$ & $\begin{array}{c}\text { Threshold } \\
\text { value }(10 \%)\end{array}$ & result \\
\hline LNIAV & 3.8666 & -2.7719 & -1.9740 & -1.6029 & unstable \\
LNIWT & -0.2855 & -2.7719 & -1.9740 & -1.6029 & unstable \\
LNIWG & 1.2715 & -2.7719 & -1.9740 & -1.6029 & unstable \\
LNIWS & -4.8604 & -5.1249 & -3.9334 & -3.4200 & smooth \\
LNINC & -3.6718 & -4.2000 & -3.1754 & -2.7290 & smooth \\
LNOPI & 0.3670 & -2.7922 & -1.9777 & -1.6021 & unstable \\
DLNIAV & -6.0432 & -5.5219 & -4.1078 & -3.5150 & smooth \\
DLNIWT & -3.0223 & -2.7922 & -1.9777 & -1.6021 & smooth \\
DLNIWG & -3.0314 & -2.7922 & -1.9777 & -1.6021 & smooth \\
DLNOPI & -5.5335 & -2.7922 & -1.9777 & -1.6021 & smooth \\
\hline
\end{tabular}

Note: D indicates first-order difference

Through the af unit root test, it is found that under the 5\% significance level, the sequences lniav, lniws, lninc and lnopi have the unit root hypothesis, while the lniws, lninc and first-order difference sequences dlniav, dlniwt, dlniwg, dlnopi are rejected. Root hypothesis.This shows that the time series of waste and noise is inherently stable, and the investment in industrial added value, wastewater, waste gas and other industrial pollution treatments is a first-order single sequence.It can be seen that the industrial added value and the waste and noise pollution control investment do not belong to the same order single sequence, and the non-same order single sequence does not meet the requirements of co-integration test.The industrial added value and the investment of wastewater, waste gas and its industrial pollution are all first-order and single-conformity, which are in line with the preconditions for co-integration test, and further test whether there is a co-integration relationship between them.

1.4 Co-integration test of industrial added value sequence and investment sequence of wastewater, waste gas and other pollution control

It is determined whether the industrial added value has a long-term equilibrium relationship with investment in wastewater pollution control, investment in waste gas pollution control and other industrial pollution control investments. This paper uses Engle-Granger co-integration test to test it separately.First, the OLS regression analysis of the sequence LNIAV with the sequence LNIWT, the sequence LNIWG and the sequence LNOPI yields the following equation:

$$
\begin{aligned}
& L N I A V=14.8778255296-0.425199207626 L N I W T+e_{t} \text {, } \\
& (5.842305) \quad(-2.018216) \\
& R^{2}=0.370228 \quad D W=1.260753 \quad F=4.073195 \\
& L N I A V=4.19781512078+0.434114640333 L N I W G+e_{t} \text {, } \\
& R^{2}=0.581310 \quad D W=1.477848 \quad F=15.27244 \\
& L N I A V=10.5831469399-0.0762251457276 L N O P I+e_{t 5} \text {. }
\end{aligned}
$$

$$
\begin{array}{ll}
(3.322524) & (-0.264057) \\
R^{2}=0.006299 & D W=0.129123 \quad F=0.069726
\end{array}
$$

From the regression equation of ols, we can see that in equation (6) $R^{2}$ The value of 0.006299 indicates that the equation has a good goodness of fit. The dw value is 0.129123 , indicating that there is a strong autocorrelation of the residual sequence.It can be seen that the correlation between industrial added value and other industrial pollution control investments is weak, and it is likely that there is no co-integration relationship, and the residual root sequence can be further tested by unit root test.

The regression residual sequence estimation model is as follows:

$$
\begin{aligned}
& e_{t 1}=L N I A V-14.8778255296+0.425199207626 L N I W T, \\
& e_{t 2}=L N I A V-4.19781512078-0.434114640333 L N I W G, \\
& e_{t 5}=L N I A V-10.5831469399+0.076225145728 L N O P I .
\end{aligned}
$$

The unit root test results of the regression residual sequence are shown in Table 2: 
Table 2 Unit root test results of residual sequences (ADF test)

\begin{tabular}{cccccc}
\hline variable & $\begin{array}{c}\text { Adf } \\
\text { value }\end{array}$ & $\begin{array}{c}\text { Threshol } \\
\mathrm{d}(1 \%)\end{array}$ & $\begin{array}{c}\text { Threshol } \\
\mathrm{d} \text { value } \\
(5 \%)\end{array}$ & $\begin{array}{c}\text { Threshol } \\
\mathrm{d} \text { value } \\
(10 \%)\end{array}$ & result \\
\hline et1 & -2.7981 & -2.7719 & -1.9740 & -1.6029 & smooth \\
et2 & -3.1135 & -2.8473 & -1.9882 & -1.6001 & smooth \\
et5 & -0.4556 & -2.8473 & -1.9882 & -1.6001 & unstable \\
\hline
\end{tabular}

At the 5\% significance level, the null hypothesis is rejected when the t-test statistic values of the residual sequences et 1 , et 2 are less than the corresponding threshold. That is to say, there is no unit root in the residual sequence, which is a stationary sequence, indicating that there is a co-integration relationship between industrial added value and industrial wastewater and industrial waste gas treatment investment. The $t$ test statistic of the residual sequence et5 is greater than the corresponding critical value, accepting the null hypothesis, indicating that there is a unit root of the residual sequence, which is a non-stationary sequence, that is, there is no agreement between the industrial added value and other industrial pollution control investments. The whole relationship further proves the inference made by the ols regression coefficient in equation (6).

1.5 Error correction model for industrial added value and investment co-integration test for industrial wastewater and waste gas treatment:

There is a co-integration relationship between industrial added value and investment in industrial wastewater and waste gas treatment, which means that there is a long-term dynamic equilibrium relationship between the two, but in the short term, there may be imbalances.In order to solve this problem and improve the accuracy of the model, the errors et 1 and et 2 of the co-integration regression equations (4) and (5) can be regarded as the equilibrium error, and the short-term behavior of industrial added value is linked with the long-term change by establishing an error correction model. stand up.According to the AIC, SC information guidelines, the error correction model is determined as follows:

$$
\Delta y_{t}=\beta_{0} \Delta x_{t-1}+\beta_{1} \Delta y_{t-1}+\gamma e c m_{t}-1+\varepsilon t .
$$

among them, $e c m_{t-1}$ It is an error correction term, that is, the residual of the previous period is used as the correction of the current period, and the error correction term is regarded as an explanatory variable in the estimated regression model:

$\triangle L N I A V_{t}=0.1549+0$.

$$
\text { (11) }
$$

0.0092

0.2142

0.2351

0.1678

$$
R^{2}=0.4086 \quad D W=2.1406
$$

$$
\Delta L N I A V_{t}=0.1347-0.0332 \Delta L N I W G_{t-1}-0.2469 \Delta L N I A V_{t-1}-0.148
$$

$$
\begin{aligned}
& 0.0255 \quad 0.6404 \quad 0.4892 \\
& R^{2}=0.3100 \quad D W=2.1555
\end{aligned}
$$

In the above estimation, the independent variable in the model (8) $\triangle L N I W T$ The regression coefficient is 0.0911 , indicating the investment level of industrial pollution wastewater treatment ( $\triangle L N I W T$ ) for every $1 \%$ increase in industrial value added $(\triangle L N I A V)$ a corresponding increase of $0.09 \%$.Independent variable in model (9) $\triangle L N I W G$ The regression coefficient is 0.0332 , indicating the investment level of industrial pollution and waste gas treatment ( $\triangle L N I W G$ ) for every $1 \%$ increase in industrial value added ( $\triangle L N I A V$ ) a corresponding decrease of $0.03 \%$. This is mainly because industrial wastewater can be used for the re-production of enterprises after treatment, and has obvious positive externalities. Industrial waste gas treatment will only increase the intermediate consumption and operating costs of the production process, and will not bring any benefits to the enterprise. The elastic coefficient of the error correction term is negative, indicating that there is an error correction mechanis $m$ in the above test. The change of industrial added value depends not only on the changes of industrial pollution wastewater and waste gas treatment investment, but also on the industrial value added to the equilibrium level of the previous period. Deviation.

1.6 Granger causality test of industrial value added sequence and investment sequence of industrial wastewater and waste gas pollution control

The Granger causality test of two variables presupposes that one of the following two conditions is satisfied: one is that both variables are stable; the other is that there is a co-integration relationship between the two non-stationary variables. The Granger causality test can only be carried out if one of the two is satisfied. If both conditions are not met, the results obtained by the Granger causality test are invalid. The research conditions in this paper satisfy the above second case, and the 
Granger causality test can be performed. Since there is no long-term equilibrium relationship between other industrial pollution control investment sequences and industrial value-added sequences, there is no need to conduct a Granger causality test. It is only necessary to test the industrial added value and the investment in industrial wastewater and waste gas pollution control. Granger causality.In this paper, the FPE optimal lag criterion proposed by Hsiao (1981) is $\mathrm{FPE}=(\mathrm{T}+\mathrm{K})$ * $\mathrm{SSR} /[\mathrm{TK}) * \mathrm{~T}$ (where $\mathrm{T}$ is the sample size, $\mathrm{K}$ is the number of estimated parameters, and SSR is the difference squared of the residual). And) to determine the lag order.

Table 3 Granger causality test of variables

\begin{tabular}{|c|c|c|c|c|}
\hline variable & Null hypothesis & $\begin{array}{c}\text { Lag } \\
\text { order }\end{array}$ & $\begin{array}{c}\text { F-stati } \\
\text { stics }\end{array}$ & $\begin{array}{c}\mathrm{p} \\
\text { value }\end{array}$ \\
\hline $\begin{array}{l}\text { LNIAV } \\
\text { LNIWT }\end{array}$ & $\begin{array}{l}\text { LNIAV is not the } \\
\text { Granger reas on for } \\
\text { LNIWT } \\
\text { LNIWT is not the } \\
\text { granger reason for } \\
\text { LNIAV }\end{array}$ & 3 & $\begin{array}{l}0.9239 \\
0.8058\end{array}$ & $\begin{array}{c}0.525 \\
2 \\
0.568 \\
4\end{array}$ \\
\hline $\begin{array}{l}\text { LNIAV } \\
\text { LNIWG }\end{array}$ & $\begin{array}{l}\text { LNIAV is not the } \\
\text { Granger reason for } \\
\text { LNIWG } \\
\text { LNIWG is not the } \\
\text { Granger reason for } \\
\text { LNIAV }\end{array}$ & 3 & $\begin{array}{l}0.3686 \\
2.6400\end{array}$ & $\begin{array}{c}0.783 \\
0 \\
0.223 \\
2\end{array}$ \\
\hline
\end{tabular}

It can be seen from Table 3 that the sequence lniav has no Granger causal relationship with lniwt and lniwg and is independent of each other.This indicates that the industrial added value of the current period cannot be predicted by the lag period of industrial wastewater and waste gas treatment investment, nor can the current investment amount of industrial wastewater and waste gas be predicted through the lag period of industrial added value.The amount of industrial enterprises invested in the treatment of industrial wastewater and waste gas pollution should be based on the current pollution situation. The total amount of input management should be determined according to actual needs. The amount of investment in the past for the treatment of pollution is not the current industrial added value. Significantly affected. The continuous trend of industrial added value cannot determine the pollution status of industrial wastewater and waste gas, thus determining the investment of enterprises in the treatment of wastewater and waste gas.

\section{CONCLUSIONS AND RECOMMENDATIONS}

Research conclusions: Through the research on the long-term dynamic equilibrium relationship between the industrial added value of the sample interval of China's industry in 2005-2018 and the added value of industrial wastewater, waste gas, waste solidification, noise and other industrial pollution, industrial added value and industrial wastewater and waste gas can be obtained. There is a co-integration relationship between pollution control investments. In the short term, industrial pollution wastewater treatment investment ( $\triangle L N I W T$ ) For every $1 \%$ increase in level, industrial added value ( $\triangle L N I A V$ ) The level is increased by $0.09 \%$, and the investment in industrial pollution and waste gas treatment ( $\triangle L N I W G$ ) For every $1 \%$ increase in level, industrial added value ( $\triangle L N I A V$ The level drops by $0.03 \%$.This shows that in the short term, industrial wastewater pollution control investment has a positive pulling effect on industrial added value, while industrial waste gas pollution control investment has a negative pulling effect on industrial added value, which is consistent with objective reality.There is no co-integration relationship between industrial added value and industrial waste, noise and other industrial pollution control investments.The Granger causality test shows that there is no Granger causality between industrial added value and investment in industrial wastewater and waste gas pollution control.

Research implications: Based on the above analysis, it can be seen that the effect of the investment funds invested in different types of industrial pollution on industrial added value is also different. In the short term, industrial wastewater treatment investment has a positive pulling effect on industrial added value, while industrial waste gas treatment investment has a negative effect on industrial added value. In addition, there is no co-integration relationship between waste, noise and other pollutant treatment investments and industrial added value. However, in terms of investment in wastewater treatment with a positive pull-in effect on industrial value added, the return on investment is also very low. Under the "three simultaneous" conditions, China put forward the idea of "who pollutes and who governs". The internal capital of enterprises is more than $85 \%$ of the annual investment in industrial pollution control. As the investment demand for industrial pollution control is constantly expanding, it is difficult to reach the environmental governance investment demand by relying solely on internal funds. Moreover, it is difficult to mobilize the enthusiasm of corporate governance for the use of internal funds for pollution control, which requires the joint efforts of the government and enterprises as well as social groups. The corporate governance funds generally include internal funds and bank loans. In order to improve the enthusiasm of corporate governance 
investment, the Shandong provincial government's special preferential policies for enterprises should continue to be increased.The most important thing is that the principle of "who pollutes and set up governance" has little effect on the reality. Based on the actual situation in the province, it is urgent to set up a special government agency to be responsible for the related business of industrial pollution control investment, so that it can be better. The various preferential policies for government investment in corporate pollution control will be implemented. The most important thing is to integrate social resources and absorb social capital through this institution. Because environmental governance relies solely on the power of government and enterprises, it is necessary to use the power of the whole society to decompress government departments and enterprises, and let industrial enterprises control pollution. Investment from passive to active, will make pollution control effective.

\section{REFERENCES}

[1] Lin-Sea L, Choong C, Yoke-Kee E. Carboon Dioxide Emission, Institutional Quality, and Economic Growth: Empirical Evidence in Malaysia[J].Renewable Energy,2014 , (68):276-281.

[2] Zhu Jianhua, Xu Shunqing, et al. Empirical Research on China's Environ mental Protection Investment and Economic Growth-Based on Error Correction Model and Granger Causality Test [j]. China Population, Resources and Environment, 2014, (s3): 100-103.

[3] Wu Yongchao, Xie Zhengjuan. Research on the Economic Growth Effect of Pollution Control Investment in Industrial Enterprises [j]. Economic Issues, 2017, (5): 48-67.

[4] I am only fortunate. From the experience of Japan to see the investment of industrial pollution control in China [j]. Shanghai Economic Research, 2008, (12): 98-105

[5] Lan Minghui, Liao Fulin, et al. Analysis of the impact of environmental protection investment in Fujian Province on industrial wastewater pollution control [j]. Environmental Protection Technology, 2014, (1): 10-14.

[6] Liu Tao. Evaluation of Dynamic Efficiency of Urban Industrial Pollution Control Investment in Fujian Province[J]. Journal of Northwest Normal University, 2013, (4): 94-100.

[7] Nie Hualin, Chen Shaozhen. Research on Evaluation of Industrial Pollution Control Efficiency in Westem Regions [J]. Development Research, 2010, (4): 5-8.
[8] Chen Shihong, Xu Wei, Ouyang Zezheng, et al. Empirical study on the relationship between industrial pollution environmental governance investment and economic growth in China-analysis based on panel data of 10 provinces and cities [j]. Scientific Decision, 2015 (2): 43-54.

[9] Li Zi Nai, Ye Azhong. Higher Econometrics [m]. Beijing: Tsinghua University Press, 2000.

[10] Dong Huizhong, Song Hongli, et al. Co-integration analysis and error correction of total output value and energy consumption of iron and steel industry [j]. Mathematical Statistics and Management, 2009(3): 482-488

[xi] Gao Tiemei. Econometric Analysis Methods and Modeling: EViews Applications and Examples [M]. Tsinghua University Press, 2009: 177-180. 